\title{
Disorders of Sex Development: A 5-year Review of Patients at a Tertiary Care Hospital
}

\author{
Kristin Grace H. Guerrero-Gonzalez ${ }^{1}$ and Sylvia C. Estrada ${ }^{1,2}$ \\ ${ }^{1}$ Division of Clinical Genetics, Department of Pediatrics, College of Medicine and Philippine General Hospital, University of the Philippines Manila \\ ${ }^{2}$ Institute of Human Genetics, National Institutes of Health, University of the Philippines Manila
}

\begin{abstract}
Background. Disorders of Sex Development (DSD) are conditions that arise from an abnormality of the typical structural, chromosomal and/or gonadal characteristics of sex development. The incidence of DSD is not well established in the Philippines and there is no published local data. The complex nature of DSD requires streamlined multidisciplinary team management and guidelines from the 2006 Consensus meeting have become the standard of care for patients.
\end{abstract}

Objective. The study describes the phenotype, biochemical, diagnostic and management profiles of patients with Disorders of Sex Development (DSD) excluding congenital adrenal hyperplasia (CAH) at the Philippine General Hospital, a tertiary care medical facility.

Methods. Medical records of patients with DSD seen at the Division of Clinical Genetics from 2012-2016 were reviewed. Histories, demographic profiles, clinical features, co-existing health conditions, laboratory, imaging results, and interventions (medical or surgical) were recorded into a clinical report form.

Results. Fifty-five (55) patient charts were included of all the patients with DSD listed in the registry. The neonatal period was the most common time DSD was first noted (69.09\%). Most (58.18\%) were assigned the male sex. The most common genital anomalies were hypospadias (45.45\%), cryptorchidism (21.82\%), and micropenis (12.73\%). Associated health conditions included multiple congenital anomalies (32.73\%), genitourinary with or without gastrointestinal anomalies (16.36\%) and dysmorphic features (12.73\%). Among 28 patients with karyotypes, there were 12 patients with sex chromosome DSD; two 46, XX DSD and fourteen 46, XY DSD. Four patients were prescribed hydrocortisone, three of whom had higher levels of 17-OH progesterone beyond cut-off level ( 2 preterm, 1 full term) while 1 full term presented with genital ambiguity; one case of Klinefelter syndrome was given testosterone replacement. Ten patients underwent corrective surgery for urogenital anomalies. Repair of hypospadias was the most common procedure. Repairs of associated anomalies (neurologic, cardiac, gastrointestinal, genitourinary) were done in 6 patients.

Conclusion. Complete history, meticulous physical examination and comprehensive investigations are important for the confirmation of DSDs. Uniform classification, use of standardized terminology, and proper documentation of findings are crucial for the integrated and appropriate management of these patients.

Key Words: Disorders of sex development, ambiguous genitalia, genital anomalies

\section{INTRODUCTION}

Corresponding author: Kristin Grace H. Guerrero-Gonzalez, MD Division of Clinical Genetics

Department of Pediatrics

Philippine General Hospital

University of the Philippines Manila

Taft Avenue, Manila 1000, Philippines

Email: kgguerrero-gonzalez@post.upm.edu.ph
Disorders of Sex Development (DSD) are rare conditions characterized by an abnormality of the physical, chromosomal, and/or gonadal features that typically define sex development. ${ }^{1}$ The term DSD was defined at the Chicago Consensus Meeting in 2005, as a "congenital discrepancy between the external genitalia or anatomic sex, gonadal and chromosomal sex. ${ }^{2,3}$ The primary genetic defect is the basis of the new nomenclature which includes 
3 categories: (1) Sex chromosome DSD, (2) 46, XX DSD, and (3) 46, XY DSD. This provides a more systematic approach to diagnosis and integrates a variety of conditions presenting with DSD. ${ }^{4}$

The genotype-phenotype correlation remains indefinable as studies demonstrate the high variability in the clinical, biochemical, histological and genetic characteristics. ${ }^{5,6}$ When mutations occur in gonad-specific regulatory regions of genes, symptoms are confined to organs of sex development. Most genes influencing the developing gonad are also expressed in other organs and may lead to syndromic DSDs. ${ }^{78} \mathrm{~A}$ meticulous physical examination is, therefore, necessary to identify syndromes associated with DSDs. ${ }^{9}$ A detailed description of the external genitalia should include symmetry, labial hyperpigmentation, presence of gonads, ambiguity, measurement of the phallus, location of the urethral meatus, and perineal opening. ${ }^{10}$ Cloacal abnormalities, hypospadias, anorectal malformation, and other urogenital anomalies should be assessed. ${ }^{11}$ The onset of puberty and presence of secondary sexual characteristics should be noted since DSDs may present beyond the newborn period. Other presentations include inguinal or labial masses, progressive clitoromegaly, pubertal virilization or delayed/incomplete puberty. Common features of VACTER/VACTERL association, Turner syndrome, Klinefelter syndrome, Mayor-Rokitansky-Kuster-Hauser and Denys-Drash syndrome should be searched for. ${ }^{12-14}$

No single evaluation protocol for DSDs can be universally recommended because of the broad spectrum of findings. Karyotype, biochemical or hormonal studies such as 17-hydroxyprogesterone, testosterone, estrogen, gonadotropins, anti-Müllerian hormone, and serum electrolytes are among the first to be requested. ${ }^{2}$ More commonly requested imaging modalities include abdomino-pelvic ultrasound, voiding cystourethrogram and genitogram. Magnetic resonance imaging and CT scan of the abdomen provide a more detailed study of the urogenital anatomy and to evaluate for DSD-associated malignancies or tumors. ${ }^{15}$ Advances in molecular analysis will ultimately aid in characterizing the specific molecular etiology of DSDs. ${ }^{16}$

Management is individualized and must target the primary etiology while addressing the medical, surgical and psychological aspects. The American Academy of Pediatrics recommends genitoplasty between 2 and 6 months of age. Although early corrective genital surgery is controversial, some studies report satisfactory outcomes. ${ }^{17}$ Sex assignment is a concern, and factors known to influence it include underlying etiology, appearance of the genitalia, options for surgery, hormone replacement therapy, fertility, family's opinion, and cultural practices. ${ }^{3}$ To date, there is no consensus regarding the indications, timing, procedure and assessment of surgical outcome. ${ }^{18}$ Pharmacologic therapy such as testosterone and estrogen may be indicated for hypogonadism. ${ }^{19,20}$
There has been no published review of DSD in the local setting. In view of this, the main objective of this study was to describe pediatric patients with DSD referred to the Clinical Genetics section of PGH. The data generated may identify factors that enable or hinder the early diagnosis and optimal treatment of DSD in a limited resource setting like the Philippines.

\section{METHODS}

\section{Study Design and Population}

This was a review of the medical charts of pediatric patients ( $0-18$ years old) with DSD referred to the Division of Clinical Genetics from 2012 to 2016. Patients with physical features of DSD, either isolated or associated with multiple congenital anomalies, and those with a confirmed diagnosis of the condition based on physical examination, laboratory (hormonal assay, karyotype, histopathology) and/or diagnostic imaging results (ultrasound, CT scan, MRI) were included in the study. Patients whose medical records were not available for review were excluded. This study did not include patients diagnosed with congenital adrenal hyperplasia (CAH).

\section{Data Collection}

Data collection commenced after the protocol was approved by the institutional ethics board. The data was recorded in data collection forms. This included: history, age at presentation and first consult, sex of rearing, reason for consult, family history of consanguinity or DSD; physical examination findings of dysmorphisms, anthropometric data, external genitalia, presence of gonads, secondary sex characteristics; health problems such as tumors or associated anomalies; results of laboratory and diagnostic imaging (ultrasound, computed tomography or magnetic resonance imaging), hormone measurements, karyotype, gonadal histology; surgery and/or medical management; and gender reassignment. With regards the type of DSD, patients were grouped into 3 categories based on the 2006 Chicago consensus. Patients without laboratory and diagnostic workup but with features of DSD were categorized as "unclassified". The data collection forms were kept in a locked cabinet with access only to the study proponents.

\section{Data Analysis}

Descriptive statistics (frequency, percentages, frequency counts) were applied to the data.

\section{RESULTS}

Of the 6526 patients evaluated by the section of Clinical Genetics from 2012-2016, 74 (1.1\%) was diagnosed as DSD or had features thereof and were eligible for inclusion. However, only 55 patient charts were available for review. 


\section{Historical Profile}

\section{Age at Initial consultation}

Thirty patients $(54.5 \%)$ had their first consult during infancy; $4(7.3 \%)$ as toddlers; $6(10.9 \%)$ and $8(14.5 \%)$ were preschool and school-age children, respectively, and 7 (12.7\%) during adolescence (Table 1).

\section{Sex assignment}

Thirty-two (58.2\%) were assigned as males, 18 (32.7\%) as females, and 5 (9.1\%) had no sex assignment.

\section{Reason for consultation}

Ambiguous genitalia in 16 patients (29.1\%) was the most common chief complaint followed by multiple congenital anomalies (18.2), hypospadias (11\%) and Turner syndrome (11\%) (Table 1).

\section{Consanguinity}

Ninety-one percent of patients had no consanguinity.

\section{Family history}

One had a family history of genital ambiguity.

\section{Clinical Characteristics}

External genitalia were normal in 12 patients (10 female and 2 male). Forty-two had anomalies of the external genitalia, 25 (45.4\%) of whom had hypospadias. External genitalia were not specifically described in one case.

Table 1. Historical profile of 55 DSD patients

\begin{tabular}{|c|c|c|}
\hline Variable & $\begin{array}{l}\text { No. of } \\
\text { patients }\end{array}$ & $\%$ \\
\hline $\begin{array}{l}\text { * Age at first consult: } \\
\text { Infancy (0-1 yr.) } \\
\text { Toddler (2-3 yr.) } \\
\text { Preschool (4-6 yr.) } \\
\text { School age (7-11 years) } \\
\text { Adolescence (12-18 years) }\end{array}$ & $\begin{array}{r}30 \\
4 \\
6 \\
8 \\
7\end{array}$ & $\begin{array}{r}54.5 \\
7.3 \\
10.9 \\
14.5 \\
12.7\end{array}$ \\
\hline $\begin{array}{l}\text { Sex of rearing } \\
\text { Male } \\
\text { Female } \\
\text { Not indicated }\end{array}$ & $\begin{array}{r}32 \\
18 \\
5 \\
\end{array}$ & $\begin{array}{r}58.2 \\
32.7 \\
9.1 \\
\end{array}$ \\
\hline $\begin{array}{l}\text { Reason for consult: } \\
\text { Ambiguous genitalia } \\
\text { Genital anomalies } \\
\text { Hypospadias (6); Cryptorchidism (1) }\end{array}$ & $\begin{array}{r}16 \\
7\end{array}$ & $\begin{array}{l}29.1 \\
12.7\end{array}$ \\
\hline $\begin{array}{l}\text { Features of Turner Syndrome } \\
\text { Gastrointestinal tract anomaly } \\
\text { Imperforate anus + genital anomalies (3); } \\
\text { Imperforate anus alone (2) }\end{array}$ & $\begin{array}{l}6 \\
5\end{array}$ & $\begin{array}{r}10.9 \\
9.1\end{array}$ \\
\hline $\begin{array}{l}\text { Genitourinary anomaly } \\
\text { Bladder exstrophy (3); Cloacal exstrophy (1) }\end{array}$ & 4 & 7.3 \\
\hline $\begin{array}{l}\text { Others: } \\
\text { Multiple congenital anomalies (10), } \\
\text { dysmorphic features (3), possible inborn error } \\
\text { of metabolism (1); abnormal karyotype (1); } \\
\text { Müllerian anomalies (2) }\end{array}$ & 17 & 31 \\
\hline
\end{tabular}

\footnotetext{
${ }^{*}$ Age stage. ${ }^{21}$
}

The most common associated co-morbidity was multiple congenital anomalies (18/55 or $32.7 \%)$. Eleven had dysmorphic features and 1 had short stature and delayed secondary sex characteristics. (Table 2).

\section{Laboratory and Diagnostic Profiles}

Only 28 of the 55 patients had karyotype results: 12 sex chromosome DSD, 14 were 46, XY DSD and 2 were 46, XX DSD. The remaining 27 were not categorized into the specific DSD due to lack of karyotype, and limited data.

Turner syndrome (TS) was the most common (5) etiology of sex chromosome DSD. There were 4 patients with mixed gonadal dysgenesis and 2 patients with Klinefelter syndrome.

The etiologic diagnosis in 14 cases of 46, XY DSD could not be determined due to lack of hormone and imaging data. Table 3 summarizes the karyotype, laboratory and imaging results of the 28 patients with DSD.

Table 2. Genito-urinary features of 55 patients with DSD

\begin{tabular}{|c|c|c|}
\hline Clinical parameter & $\begin{array}{l}\text { No. of } \\
\text { patients }\end{array}$ & $\%$ \\
\hline \multicolumn{3}{|l|}{ External genitalia appearance } \\
\hline Hypospadias & 25 & 45.4 \\
\hline Normal female genitalia & 10 & 18.2 \\
\hline Micropenis & 7 & 12.7 \\
\hline Ambiguous & 6 & 10.9 \\
\hline Normal male genitalia & 2 & 3.6 \\
\hline Epispadias + micropenis & 1 & 1.8 \\
\hline Shawl scrotum & 1 & 1.8 \\
\hline Clitoromegaly alone & 1 & 1.8 \\
\hline $\begin{array}{l}\text { Clitoromegaly, labial hypoplasia and absent } \\
\text { vaginal opening }\end{array}$ & 1 & 1.8 \\
\hline Not specified & 1 & 1.8 \\
\hline \multicolumn{3}{|l|}{ Gonads } \\
\hline Palpable, bilateral & 21 & 38.2 \\
\hline Non-palpable (female phenotype) & 4 & 7.3 \\
\hline Cryptorchidism (unilateral/bilateral) & 16 & 29.1 \\
\hline Not specified & 14 & 25.4 \\
\hline \multicolumn{3}{|l|}{ Associated co-morbidities } \\
\hline a. Multiple congenital malformations & 18 & 32.7 \\
\hline b. None & 12 & 21.8 \\
\hline $\begin{array}{l}\text { c. Genitourinary \& gastrointestinal anomalies } \\
\text { Cloacal exstrophy sequence (3) }\end{array}$ & 12 & 21.8 \\
\hline \multicolumn{3}{|l|}{ Renal cysts \& chronic kidney disease (1) } \\
\hline \multirow{2}{*}{\multicolumn{3}{|c|}{$\begin{array}{l}\text { Bladder exstrophy sequence (1) } \\
\text { Patent urachus with hydronephrosis (1) }\end{array}$}} \\
\hline & & \\
\hline \multicolumn{3}{|l|}{$\begin{array}{l}\text { Patent urachus, imperforate anus, colonic } \\
\text { atresia, duplicated cecum (1) }\end{array}$} \\
\hline \multicolumn{3}{|l|}{$\begin{array}{l}\text { Renal agenesis, ureterocoele, septated } \\
\text { bladder with diverticula (1) }\end{array}$} \\
\hline \multicolumn{3}{|l|}{ Bilateral hydrocoele (1) } \\
\hline Imperforate anus (3) & & \\
\hline d. Dysmorphic features & 9 & 16.3 \\
\hline Hearing loss & 1 & 1.8 \\
\hline Congenital heart disease & 1 & 1.8 \\
\hline $\begin{array}{l}\text { e. Short stature and delayed secondary sex } \\
\text { characteristics }\end{array}$ & 1 & 1.8 \\
\hline f. Congenital heart disease & 1 & 1.8 \\
\hline
\end{tabular}


Table 3. Karyotype, biochemical, and imaging results of 28 patients with DSD

\begin{tabular}{|c|c|c|c|}
\hline Patient & Karyotype & Genitourinary imaging & Hormonal profile \\
\hline P1 & $46, X, I(x)(q 10)$ & ND & ND \\
\hline $\mathrm{P} 2$ & $46, X$, add $(x)(q 22)$ & Hypoplastic uterus, streak gonads & N Estradiol, $\uparrow \mathrm{LH}, \uparrow F S H$ \\
\hline P3 & $45, \mathrm{X}$ & ND & ND \\
\hline P4 & $45, x$ & ND & ND \\
\hline P5 & $45, x$ & ND & ND \\
\hline P6 & $45, X / 46, X Y$ & Absent uterus, $(+)$ right testis, non-visualized left testis & $\uparrow 17-\mathrm{OHP}$ \\
\hline P7 & $45, X / 46, X Y$ & (+) uterus, gonads within labioscrotal area & N 17-OHP, N Estradiol, $\uparrow L H, \uparrow F S H$ \\
\hline P8 & $\begin{array}{l}45 X / 46 X Y \\
+ \text { marker }\end{array}$ & $\begin{array}{l}\text { Infantile uterus, undescended left testicle, } \\
\text { underdeveloped right testicle }\end{array}$ & $\begin{array}{c}\text { N 17-OHP, } \uparrow \text { testosterone, } \\
\text { N estradiol, N LH, } \uparrow \text { FSH }\end{array}$ \\
\hline P9 & $47, X Y Y / 45, X$ & Absent uterus, present left testis, absent right testis & sl. $\downarrow 17-\mathrm{OHP}$ \\
\hline P10 & $48, X X X Y$ & Bilateral testes scrotum & ND \\
\hline P11 & $48, X X X Y$ & No uterus, small testes in scrotum & $\mathrm{N}$ testosterone, $\mathrm{N}$ estradiol, $\uparrow \mathrm{LH}, \uparrow \mathrm{FSH}$ \\
\hline P12 & $47, X Y Y$ & Left testis within inguinal region, direct inguino-scrotal hernia, right & ND \\
\hline P13 & $46, X Y$ & $\begin{array}{c}\text { No data on Müllerian structures, } t / c \text { rudimentary } \\
\text { or atrophic gonads (UTS-IS) }\end{array}$ & N 17-OHP \\
\hline P14 & $46, X Y$ & ND & ND \\
\hline P15 & $46, X Y$ & Present vagina, absent uterus, absent ovaries & $\begin{array}{l}\text { N 17-OHP, N testosterone, N LH, } \\
\uparrow \text { FSH, N 11-deoxycortisol }\end{array}$ \\
\hline P16 & $46, X Y$ & No uterus, left testis in inguinal area, right testis in scrotal sac & $\uparrow$ testosterone, N LH, N FSH \\
\hline P17 & $46, X Y$ & No uterus, undescended testis left, right within scrotal area (UTS) & ND \\
\hline P18 & $46, X Y$ & ND & ND \\
\hline P19 & $46, X Y$ & ND & ND \\
\hline $\mathrm{P} 20$ & $46, X Y$ & No uterus, testes in scrotal sac & N 17-OHP \\
\hline $\mathrm{P} 21$ & $46, X Y$ & ND & ND \\
\hline $\mathrm{P} 22$ & $46, X Y$ & ND & ND \\
\hline $\mathrm{P} 23$ & $46, X Y$ & No uterus, underdeveloped testes in inguinoscrotal area & $\begin{array}{c}\text { N 17-OHP, N testosterone, } \\
\text { Inconclusive estradiol, LH, FSH }\end{array}$ \\
\hline P24 & $46, X Y$ & ND & १17-OHP, $\uparrow 11$-deoxycortisol (preterm) \\
\hline $\mathrm{P} 25$ & $46, X Y$ & Undescended testis left, non-visualized right testis & $\mathrm{N}$ testosterone, Inconclusive $\mathrm{LH} \& \mathrm{FSH}$ \\
\hline $\mathrm{P} 26$ & $46, X Y$ & No uterus, undescended testis left, descended right testis & ND \\
\hline P27 & $46, X X$ & No uterus, left gonad in scrotal sac, right gonad in inguinal area & 个 Testosterone, $\uparrow$ estradiol, N LH, N FSH \\
\hline P28 & $46, X X$ & ND & ND \\
\hline
\end{tabular}

ND - No data.

\section{Medical and Surgical Management}

\section{Medical management}

Among the 28 patients with karyotype, one patient (P11) with Klinefelter syndrome received testosterone replacement and patient 24, a preterm (36 weeks) neonate with 46, XY DSD received short course hydrocortisone therapy. Three out of the 27 unclassified DSD received short courses of hydrocortisone for increased 17OHP due to prematurity and stress.

\section{Psychological counseling}

Seven patients (ages 3 to 17 years old) were referred for psychological counseling.

\section{Surgical management}

Six of the 28 patients with karyotype underwent surgery between 3 to 13 years of age for genitourinary anomalies and 4 were scheduled for the procedure. Data was not available regarding sex reassignment and outcome. Repair of associated anomalies involving other organ systems (neurologic, cardiac, gastrointestinal, urinary tract) was done in 4 cases of 46, XY DSD and 11 cases of unclassified DSD. One patient with 46, XY DSD was scheduled for a kidney transplant. Table 4 summarizes the medical and surgical management in patients with DSD.

\section{DISCUSSION}

The broad and variable clinical spectrum of DSD is due to the expansion of its definition. ${ }^{3}$ In our study, the most common external genital anomalies were hypospadias (45.45\%), followed by micropenis (12.73\%) and ambiguous genitalia (10.91\%). In contrast, Fragoso et al. reported genital ambiguity to be more common (45\%). In their study, undescended testes were present in $28.75 \%$, similar to our population (29.10\%). ${ }^{22}$ Several factors, such as low birth weight and multiple gene polymorphisms, have been 
Table 4. Management of patients with DSD

\begin{tabular}{|c|c|c|c|}
\hline Category of DSD & Medical & $\begin{array}{l}\text { Psychological } \\
\text { Counseling } \\
\text { (Yes or No) }\end{array}$ & Surgical (Genitourinary) \\
\hline \multicolumn{4}{|l|}{ A. Sex chromosome DSD } \\
\hline \multicolumn{4}{|c|}{ Mixed gonadal dysgenesis } \\
\hline P7 & & Yes & Repair of hypospadias, vaginoscopy, gonadectomy, hysterectomy \\
\hline P9 & & Yes & Exploratory laparotomy \\
\hline \multicolumn{4}{|l|}{ Klinefelter syndrome } \\
\hline P11 & Testosterone replacement & Yes & \\
\hline \multicolumn{4}{|l|}{ B. 46, XY DSD } \\
\hline P15 & & Yes & \\
\hline P16 & & & Orchidopexy, urethroplasty \\
\hline P20 & & & Repair of hypospadias, hydrocoelectomy \\
\hline P21 & & & $\begin{array}{l}\text { Hydrocoelectomy, urethroplasty, repair of hypospadias, release } \\
\text { of chordee }\end{array}$ \\
\hline P22 & & & Repair of hypospadias, bilateral orchidectomy \\
\hline P24 & Hydrocortisone & & \\
\hline P25 & & Yes & \\
\hline P26 & & & Repair of bilateral hernia, repair of hypospadias, orchidopexy \\
\hline \multicolumn{4}{|l|}{ C. $46, \mathrm{XX}$ DSD } \\
\hline $\begin{array}{l}\text { Ovotesticular DSD } \\
\text { P27 }\end{array}$ & & Yes & $\begin{array}{l}\text { Diagnostic laparotomy, left scrotal area; Excision of right inguinal } \\
\text { mass/gonadectomy }\end{array}$ \\
\hline \multicolumn{4}{|l|}{ D. Unclassified DSD } \\
\hline P33 & & & Repair of hypospadias \\
\hline P35 & & Yes & \\
\hline P37, P40, P44 & Hydrocortisone & & \\
\hline P49 & & & Bilateral herniotomy \\
\hline
\end{tabular}

related to less pronounced forms of undervirilization (isolated or combined cryptorchidism and hypospadias). ${ }^{23}$ Our data showed that multiple congenital anomalies (32.73\%) were the most frequently associated health condition, similar, to the findings of Paris, et al. ${ }^{24}$

The neonatal period (36\%) was the most common time when DSDs were detected among our patients, similar to previous studies. ${ }^{2,25}$ This parallel with the top 2 reasons for consultation: ambiguous genitalia (29\%) and genital anomalies (12\%). Sex uncertainty in the newborn period is stressful and encourages early medical consultation, particularly since birth registration requires a correct sex assignment. Interestingly, Shawky's cohort of 908 DSDs had a later presentation in adolescence (36.56\%) and older than 18 years old (24.88\%) compared to only $8.7 \%$ in the neonatal period. ${ }^{26}$ The study, however, did not include data on gender assignment. Hughes et al. showed that DSD may be diagnosed at birth in those presenting with genital ambiguity, while DSD with typical genitalia that is either male or female may be diagnosed later. ${ }^{27}$

In our study, only 28 of the 55 patients or $51 \%$ had a karyotype. 46, XY DSD was the most common finding; however, the specific underlying etiology could not be identified due to the lack of data from diagnostic workup. Previous studies show a predominance of 46, XX DSD
(17\%) secondary to 21-hydroxylase deficiency $\mathrm{CAH}$ and a wider range of diagnosis for $46, \mathrm{XY}$ DSD (17\%) due to androgen insensitivity syndrome and gonadal dysgenesis. ${ }^{24}$ $46, \mathrm{XX}$ has also been found to be the most common karyotype in ovotesticular DSD observed in 65-90\% of cases in several studies. ${ }^{28}$ The most prevalent type of DSD in our study cannot be ascertained without the baseline karyotype; therefore, succeeding diagnostic studies were not streamlined, making results difficult to interpret. Our study did not include patients with $\mathrm{CAH}$ because those who screen positive on newborn screening are referred directly to the endocrine service; hence, they are not listed in the genetics registry. Therefore, with $\mathrm{CAH}$ patients not being part of our cohort, it may underestimate the prevalence of 46,XX DSDs.

Hormonal profile and genito-urinary imaging are also routinely requested as part of the workup for DSD. In our data, only 17 of 28 patients had results for genitourinary imaging, and only 18 of the 28 had hormone profiles. Completion of diagnostic evaluation for DSD continues to be a challenge in a limited resource setting like the Philippines, more so in an institution that caters to economically disadvantaged patients. While these patients may be recognized as early as the neonatal period, it takes several months to years for a family to comply with the 
diagnostic evaluation. Therefore these individuals are subjected to extreme delays in the definitive management. Several studies in developing countries also report challenges in identifying specific etiologies of DSD primarily due to lack in metabolic, hormonal and genetic workup; lack of specialists and centers with laboratories able to carry out diagnostic investigations. ${ }^{29,30}$ Limitations to molecular confirmation of DSD are generally due to its cost and accessibility. ${ }^{3}$ In our study, clinical parameters were used to suspect DSDs, but the absence of an etiologic diagnosis hinders streamlined management for these patients. It is an open diagnostic dilemma and prevents prompt optimal care.

Management remains complex due to ethical, diagnostic and prognostic challenges that affect decisionmaking. Hormonal replacement may be straightforward, as was the case in patient 11 (Klinefelter syndrome), who received testosterone replacement therapy. Supplementation in adolescents has been advocated in some studies to facilitate sexual development and prevent consequences of hypogonadism. ${ }^{31}$ Short course hydrocortisone therapy was given to a preterm neonate with 46, XY DSD presenting with multiple congenital anomalies, micropenis, elevated 17-OHP and 11-deoxycortisol. Transient elevations of 17-OHP have been shown to occur in premature, low birth weight and critically ill infants. This could be due to decreased clearance secondary to immature liver function, immature adrenal glands, or stress, especially if the sample was collected at less than 1 day of life. ${ }^{32-34}$ Results, therefore, should be interpreted within these contexts. Among the 28 patients with karyotype, 7 underwent surgical intervention for genitourinary anomalies, and 3 were scheduled for surgery. There is still no consensus on its surgical management; however, the following has been agreed by most experts: 1) multidisciplinary team management in specialized centers ${ }^{35} 2$ ) practicing a conservative approach with regards the gonads of patients with complete AIS;36,37 3) avoiding vaginal dilatation in childhood; 4) conserving asymptomatic Müllerian remnants during childhood which can be moved at a later period if warranted; ${ }^{38} 5$ ) removal of streak gonads after confirmation with biopsy, ${ }^{37}$ and preservation of the male gender in individuals with $46, \mathrm{XY}$ cloacal exstrophy. ${ }^{39,7}$

\section{CONCLUSION}

The new classification of DSD has led to a broader inclusion of cases based on etiology. The clinical profile of our cohort exhibited a wide spectrum of manifestations not limited to the external genitalia but also included complex malformations, making the diagnosis challenging.

It is essential for primary physicians to acquire the basic knowledge and skill of early recognition of DSD. This will facilitate multispecialty care focused towards sex assignment, psychosocial adaptation, medical and surgical management. Psychological distress may be minimized through constant coordination and open communication between the family members and the healthcare team. A carefully planned comprehensive clinical and laboratory evaluation, uniform classification and an integrated approach by the team form the cornerstone of management of DSDs. Although financial resources may be limited, the need for the karyotype and genitourinary imaging through ultrasound or CT scan are essential to diagnosis. Efforts to do these diagnostic labs should be prioritized.

Our study is limited by several factors because of its retrospective nature: data collected may not be accurate, may have inconsistency in findings and recording by different physicians handling the case, may be incomplete and difficult to interpret. There is no way to determine if the diagnostic laboratory was done if the results are not incorporated in the chart. Further, the limited sample size will not allow us to draw any viable conclusions. For a more realistic description of the spectrum of DSDs seen by the Clinical Genetics Division, a more detailed and standardized documentation of findings, integration of findings among co-managing physicians, meticulous biochemical/hormonal screening and molecular or multigene-based testing are necessary. This will lead to a definite diagnosis in patients with DSD and the discovery of novel forms causing complex genetic abnormalities.

\section{Statement of Authorship}

The final paper has been approved for submission by all authors.

\section{Author Disclosure}

All authors declared no conflicts of interest.

\section{Funding Source}

This paper was funded by the College of Medicine, University of the Philippines Manila.

\section{REFERENCES}

1. Kyriakou A, Lucas-Herald AK, McGowan R, Tobias ES, Ahmed SF. Disorders of sex development: advances in genetic diagnosis and challenges in management. Adv Genomics Genet. 2015; 5:165-77.

2. Kim KS, Kim J. Disorders of sex development. Korean J Urol. 2012 Jan; 53(1):1-8.

3. Houk CP, Hughes IA, Ahmed SF, Lee PA. Summary of consensus statement on intersex disorders and their management. Pediatrics. 2006 Aug; 118(2):753-7.

4. Pasterski V, Prentice P, Hughes IA. Impact of the consensus statement and the new DSD classification system. Best Pract Res Clin Endocrinol Metab. 2010 Apr; 24(2):187-95.

5. Camats N, Pandey AV, Fernandez-Cancio M, Andaluz P, Janner $\mathrm{M}$, Toran N, et al. Ten novel mutations in the NR5A1 gene cause disordered sex development in 46, XY and ovarian insufficiency in 46, XX individuals. J Clin Endocrinol Metab. 2012 Jul; 97(7):E1294-306.

6. Erdogan S, Kara C, Ucakturk A, Aydin M. Etiological classification and clinical assessment of children and adolescents with disorders of sex development. J Clin Res Pediatr Endocrinol. 2011; 3(2):77-83.

7. Lourenco D, Brauner R, Rybczynska M, Nihoul-Fékété C, McElreavey $\mathrm{K}$, Bashamboo A. Loss of function mutation in GATA4 causes anomalies of human testicular development. Proc Natl Aca Sci. USA. 2011 Jan; 108(4):1597-602. 
8. Benko S, Gordon CT, Mallet D, Sreenivasan R, Thauvin-Robinet $\mathrm{C}$, Brendehaug A, et al. Disruption of a long distance regulatory region upstream of SOX9 in isolated disorders of sex development. J Med Genet. 2011 Dec; 48(12):825-30.

9. Fluck CE, Pandey AV, Huang N, Agrawal V, Miller WL. P450 oxidoreductase deficiency - a new form of congenital adrenal hyperplasia. Endocr Dev. 2008; 13:67-81.

10. Dean A, Sharpe RM. Clinical review: Anogenital distance or digit length ratio as measures of fetal androgen exposure: relationship to male reproductive development and its disorders. J Clin Endocrinol Metab. 2013 Jun; 98(6):2230-8.

11. Hutson JM, Grover SR, O'Connell M, Pennell SD. Malformation syndromes associated with disorders of sex development. Nat Rev Endocrinol. 2014 Aug; 10(8):476-87.

12. Lee P, Nordenstrom A, Houk CP, Ahmed SF, Auchus R, Baratz A, et al. Global disorders of sex development update since 2006: perceptions, approach and care. Horm Res Paediatr. 2016; 85(3):158-80.

13. Farrugia MK, Sebire NJ, Achermann JC, Eisawi A, Duffy PG, Mushtaq I. Clinical and gonadal features and early surgical management of 45,X/46,XY and 45,X/47,XYY chromosomal mosaicism presenting with genital anomalies. J Pediatr Urol. 2013 Apr; 9(2):139-44.

14. Groth KA, Skakkebaek A, Hest C, Gravhold CH, Bojesen A. Clinical review: Klinefelter syndrome - a clinical update. J Clin Endocrinol Metab. 2013 Jan; 98(1):20-30.

15. Moshiri M, Chapman T, Fechner PY, Dubinsky TJ, Shnorhavorian $\mathrm{M}$, Osman S, et al. Evaluation and management of disorders of sex development: multidisciplinary approach to a complex diagnosis. Radiographics. 2012 Oct; 32(6):1599-618.

16. Bashamboo A, Ledig S, Wieacker P, Achermann JC, McElreavey K. New technologies for the identification of novel genetic markers of disorders of sex development (DSD). Sex Dev. 2010 Sep; 4(4-5): 213-24.

17. Warne G, Grover S, Hutson J, Sinclair A, Metcalfe S, Northam E, et al. A long-term outcome study of intersex conditions. J Pediatr Endocrinol Metab. 2005 Jun; 18(6):555-67.

18. Mouriquand PDE, Gorduza DB, Gay CL, Meyer-Bahlburg HFL, Baker L, Baskin LS, et. al. Surgery in disorders of sex development (DSD) with a gender issue: If (why), when, and how? J Pediatr Urol. 2016 Jun;12(3):139-49.

19. Warne GL, Grover S, Zajac JD. Hormonal therapies for individuals with intersex conditions: protocol for use. Treat Endocrinol. 2005; 4(1):19-29.

20. Drobac S, Rubin K, Rogol AD, Rosenfield RL. A workshop on pubertal hormone replacement options in the United States. J Pediatr Endocrinol Metab. 2006 Jan; 19(1):55-64.

21. Kleigman RM, Stanton BF, St Geme III JW, Schor NF, Behrman RE. Nelson Textbook of Pediatrics, 20th Ed. Philadelphia, Pennsylvania: Elsevier; 2016.

22. Gazzaneo IFP, Costa de Queiroz CM, Goes LCV, Lessa VJC, Filho RLO, do Nascimento DLL, et al. Profile of patients with genitourinary anomalies treated in a clinical genetics service in the Brazilian unified health system. Rev Paul Pediatr. 2016 Jan-Mar; 34(1):91-8.

23. Van der Zanden LFM, Van Rooij IALM, Feitz WFJ, Knight J, Donders ART, Renkema KY, et al. Common variants in DGKK are strongly associated with risk of hypospadias. Nat Genet. 2011 Jan; 43(1):48-50.
24. Parisi MA, Ramsdell LA, Burns MW, Carr MC, Grady RE, Gunther DF, et al. A gender assessment team: experience with 250 patients over a period of 25 years. Genet Med. 2007 Jun; 9(6):348-57.

25. Brain CE, Creighton SM, Mushtag I, Carmichael PA, Barnicoat A, Honour JW, et al. Holistic management of DSD. Best Pract Res Clin Endocrinol Metab. 2010 Apr; 24(2):335-54.

26. Shawky RM, Nour El-Din SM. Profile of disorders of sexual differentiation in the Northeast region of Cairo, Egypt. Egypt J Med Hum Genet. 2012 Jun; 13(2):197-205.

27. Hughes IA. Disorders of sex development: a new definition and classification. Best Pract Res Clin Endocrinol Metab. 2008 Feb; 22(1):119-34.

28. Matsui F, Shimada K, Matsumoto F, Itesako T, Nara K, Ida S, et al. Long-term outcome of ovotesticular disorder of sex development: a single center experience. Int J Urol. 2011 Mar; 18(3):231-6.

29. Chowdhury TK, Kabir M, Chowdhury MZ, Hutson JM, Banu T. The challenges in diagnosis and gender assignment in disorders of sex development presenting to paediatric surgical unit in a developing country: The role of laparoscopy and simple tests for gender identity. J Pediatr Urol. 2014 Dec; 10(6):1255-60.

30. Abdullah MA, Saeed U, Abass A, Lubna K, Weam A, Ali AS, et al. Disorders of sex development among Sudanese children: 5-year experience of a pediatric endocrinology clinic. J Pediatr Endocrinol Metab. 2012; 25(11-12):1065-72.

31. Radicioni AF, Ferlin A, Balercia G, Pasquali D, Vignozzi L, Maggi $\mathrm{M}$, et al. Consensus statement on diagnosis and clinical management of Klinefelter syndrome. J Endocrinol Invest. 2010 Dec; 33(11):839-50.

32. Nordenström A, Wedell A, Hagenfeldt L, Marcus C, Larsson A. Neonatal screening for congenital adrenal hyperplasia: 17-hydroxyprogesterone levels and CYP21 genotypes in preterm infants. Pediatrics. 2001 Oct; 108(4):E68

33. Alves CA, Junior VB, Toralles MB. Neonatal screening for congenital adrenal hyperplasia: considerations regarding the transient rise of the 17-hydroxyprogesterone. Braz J Promot (RBPS). 2006; 19(4):203-8.

34. Nomura S. Immature adrenal steroidogenesis in preterm infants. Early Hum Dev. 1997 Oct; 49(3):225-33.

35. Ahmed SF, Achermann JC, Arlt W, Balen AH, Conway G, Edwards $Z L$, et al. UK guidance on the initial evaluation of an infant or an adolescent with a suspected disorder of sex development. Clin Endocrinol (Oxf). 2011 Jul; 75(1):12-26.

36. Bouvattier C. Androgen receptor defects: syndromes of androgen insensitivity. Disorders of sex development: endocrine aspects; In Gearhart J, Rink R, Mouriquand P (eds): Pediatric Urology, ed 2. Philadelphia, Saunders Elsevier. 2010. p 472-3.

37. van der Zwan YG, Biermann K, Wolffenbuttel KP, Cools M, Looijenga LHJ. Gonadal maldevelopment as risk factor for germ cell cancer: towards a clinical decision model. Eur Urol. 2015 Apr; 67(4):692-701.

38. Josso N, Belville C, di Clemente N, Picard JY. AMH and AMH receptor defects in persistent Müllerian duct syndrome. Hum Reprod Update. 2005 Jul-Aug; 11(4):351-6.

39. Lee PA, Houk CP, Husmann DA. Should male gender assignment be considered in the markedly virilized patient with $46, \mathrm{XX}$ and congenital adrenal hyperplasia? J Urol. 2010 Oct; 184(4 Suppl):1786-92. 